\title{
Anti-Inflammatory Nutrition as a Pharmacological Approach to Treat Obesity
}

\author{
Barry Sears ${ }^{1}$ and Camillo Ricordi ${ }^{2}$ \\ ${ }^{1}$ Inflammation Research Foundation, Marblehead, MA 01945, USA \\ ${ }^{2}$ Diabetes Research Institute, University of Miami, Miami, FL 33316, USA
}

Correspondence should be addressed to Barry Sears, bsears@drsears.com

Received 5 May 2010; Accepted 17 August 2010

Academic Editor: A. Halpern

Copyright (C) 2011 B. Sears and C. Ricordi. This is an open access article distributed under the Creative Commons Attribution License, which permits unrestricted use, distribution, and reproduction in any medium, provided the original work is properly cited.

\begin{abstract}
Obesity is a multifactorial condition resulting from improper balances of hormones and gene expression induced by the diet. Obesity also has a strong inflammatory component that can be driven by diet-induced increases in arachidonic acid. The purpose of this paper is to discuss the molecular targets that can be addressed by anti-inflammatory nutrition. These molecular targets range from reduction of proinflammatory eicosanoids to the modulation of features of the innate immune system, such as tolllike receptors and gene transcription factors. From knowledge of the impact of these dietary nutrients on these various molecular targets, it becomes possible to develop a general outline of an anti-inflammatory diet that can offer a unique synergism with more traditional pharmacological approaches in treating obesity and its associated comorbidities.
\end{abstract}

\section{Introduction}

It is becoming more evident that inflammation plays an important role in the metabolic consequences of obesity, as well as other chronic degenerative conditions [1-3]. However, the understanding of the molecular mechanisms behind the control of the inflammatory process at the genetic level is only beginning to be understood. Pharmacology allows one to determine which parts of the inflammatory process are important in treatment of obesity. However, understanding how natural components of the diet can also affect the same molecular targets as pharmacological interventions could provide attractive and cost-effective alternatives to more traditional pharmacologic interventions.

The purpose of this paper is to begin to establish linkages between diet, hormones, and genetic factors affecting inflammation, and while proposing alternative approaches for the treatment of obesity and its metabolic consequences driven by chronic low-level inflammation.

\section{A New Perspective on Obesity}

The percentage of overweight and obese individuals appears to have stabilized in the United States at about $2 / 3$ of the adult population [4]. Furthermore despite being exposed to the same obesogenic environment, about 30\% of adults appear to be resistant to the development of excess body weight. This would suggest that a strong genetic component might be involved with the current obesity epidemic. This would also indicate that there may be genetic factors that when activated by the diet could be responsible for the rapid change. Therefore it would be highly desirable to determine how dietinduced chronic low-level inflammation could impact the expression of genes that can affect fat accumulation and the metabolic consequences after its accumulation.

\section{Overview of Inflammation}

We are in a constant struggle with microbes. The inflammatory responses that developed over millions of years of evolution allow us to coexist with them and to maintain a state of wellness. Most think of inflammation in terms of the pain associated with cellular destruction that comes as a result of the inflammatory response. This is why the ancient Greeks described inflammation as the internal fire. The ancient Roman physician Celsus described inflammation as pain, swelling, redness, and heat. Those are terms still used by 
many physicians to describe the inflammatory process. Today we know the inflammatory process is a complex interaction of both the pro- and anti-inflammatory phases $[5,6]$. The pro-inflammatory phase induces pain, swelling, redness and heat, which are indicators that cellular destruction is taking place. Yet there are equally important anti-inflammatory mechanisms of the inflammation process that are necessary for cellular repair and regeneration. Only when these two phases are continually balanced, and progenitor endothelial cells can effectively repair the microtissue injury that results from inflammatory events, that molecular wellness is reestablished. However, if the pro-inflammatory phase continues at a low, but chronic level that is below the perception of pain, its presence can become a driver of many chronic diseases.

There are several events that can turn on inflammatory responses. The most obvious is microbial invasion. Injuries and burns (both chemical and radiation) can also induce the most basic components of the inflammatory response. However, we are now beginning to understand how diet can also activate the same inflammatory responses induced by microbes.

All of these different factors can turn on inflammation through the innate immune response. The primary cellular components of the innate immune system include tolllike receptors, cytokine receptors, and various transcription factors that work together to activate the expression of inflammatory genes that amplify the pro-inflammatory attack phase of inflammation.

\section{Types of Inflammation}

There are two distinct types of inflammation. The first type is inflammation resulting in acute pain. This can be considered classical inflammation. A second type of inflammation can be described as chronic low-level inflammation that is below the threshold of pain. This can be termed "silent inflammation" [7-9]. Since there is no pain associated with this type of inflammation, nothing is done to stop it, and thus it can linger for years, if not decades, causing continual organ damage. As long as appropriate reparative mechanisms and the regenerative/compensatory potential of organs and tissues are maintained, the development of chronic degenerative conditions could be prevented or delayed. However, eventually, exhaustion of the reparative/regeneration potential will occur, with subsequent organ damage, loss of function and the onset of overt chronic disease although the initiating pathogenetic events may have started decades earlier, triggered by the underlying silent inflammation process.

Both types of inflammation are primarily driven by the production of pro-inflammatory eicosanoids derived from arachidonic acid (AA). AA is an omega-6 fatty acid whose levels are entirely controlled by the diet. Antiinflammatory drugs interact with molecular targets that are downstream from AA, primarily by either inhibiting the enzymes that convert AA into pro-inflammatory eicosanoids or inhibiting the release of AA from phospholipids in the membrane. Anti-inflammatory nutrition works upstream by reducing the levels of AA. The overall goal (reduction of pro-inflammatory eicosanoids) remains the same, but the mechanisms to reach that goal are very different.

\section{Innate Immune System}

The linkage of diet and inflammation lies within the innate immune system. The innate immune system is the most primitive part of our overall immunological response. As a result, it has been conserved for hundreds of millions of years of evolution and is sensitive to nutrients [10]. More importantly, its activation of the inflammatory response is based on primitive pattern recognition. This is why the diet remains intimately connected to the regulation of inflammation. Certain food components can activate the inflammatory process of the innate immune system, and others can inhibit it. When advances in molecular biology finally began to unravel the control mechanisms inherent in the innate immune system, a more detailed understanding of unexpected mechanisms for a variety of commonly used pharmacological drugs was achieved $[11,12]$. Likewise, these same advances illustrate how the diet could affect inflammation induced by the innate immune system. Today the understanding of the linkage of toll-like receptors, signaling pathways, gene transcription factors, and silent inflammation allows nutrition to evolve to a new level of gene therapy, especially the silencing of genes involved in the generation of silent inflammation.

\section{Clinical Markers of Silent Inflammation}

It is very difficult to discuss a concept of silent inflammation if you cannot measure it, especially since there is no pain associated with it. It is only recently that new clinical markers of silent inflammation have emerged. The first of these clinical markers is high-sensitivity C-reactive protein (hsCRP). It is not a very selective marker since simple infections can raise it [13-15]. A much more selective marker of silent inflammation is the ratio of two key fatty acids in the blood. The first is the omega- 6 fatty acid arachidonic acid (AA), which is the precursor to pro-inflammatory eicosanoids. The other fatty acid is the omega- 3 fatty acid eicosapentaenoic acid (EPA), which generates anti-inflammatory eicosanoids. The higher the AA/EPA ratio in the blood, the greater the level of the silent inflammation that is likely to be found in various organs [7-9].

\section{Dietary Origin of Silent Inflammation: The Perfect Nutritional Storm}

There has not been one dietary change alone in past 30 years that has increased the levels of silent inflammation. However, there has been a convergence of three distinct dietary changes that can be termed as "The Perfect Nutritional Storm" [9]. These dietary factors include 
(i) increased consumption of refined carbohydrates,

(ii) increased consumption of refined vegetable oils rich in omega-6 fatty acids,

(iii) decreased consumption of long-chain omega-3 fatty acids.

The first of these dietary changes is the increased consumption of refined carbohydrates that has significantly increased the glycemic load of the diet. The glycemic load of a meal is defined as the amount of a particular carbohydrate that is consumed at a meal multiplied by its glycemic index $[16,17]$. Today high glycemic-index carbohydrates are not only the major components in virtually all processed foods, but also in potato, rice, and white bread products. As the cost of production of refined carbohydrates has dramatically decreased in the past 25 years, the availability of products made from these ingredients has dramatically increased [18]. Increased consumption of refined food products generates meals with a high glycemic load. This results in the increased secretion of the insulin necessary to lower the resulting postprandial rise in blood glucose [17].

However, increased insulin production alone is not sufficient to explain the rapid increase in silent inflammation. This requires the presence of another recent dietary component: the increased consumption of refined vegetable oils rich in omega- 6 fatty acids. The primary fatty acid in the most common vegetable oils is the omega- 6 fatty acid known as linoleic acid. Until the last 50 years linoleic acid has been a relatively minor component of the human diet. As an example, traditional cooking fats such as butter, lard, and olive oil contain less than 10\% linoleic acid. Common vegetable oils such as corn, soy, sunflower, and safflower contain 50\%-75\% linoleic acid. The usage of these vegetable oils has increased by more than $400 \%$ since 1980 [19]. Since refined carbohydrates and vegetable oils are now the cheapest source of calories $[18,20-22]$, it is not surprising that the combination of these two dietary trends has increased the production of AA thus leading to an epidemic increase in silent inflammation.

There is epidemiological evidence that suggests that high intake of omega- 6 fatty acids may have a potential cardiovascular benefit $[23,24]$. However, this epidemiological hypothesis was tested in a carefully controlled secondary prevention trial $[25,26]$. This study, known as the Lyon Diet Heart Study, placed patients who already had a previous heart attack into one of two intervention groups. The first group followed a diet rich in omega- 6 fatty acids following the American Heart Association dietary guidelines. The other group followed a diet that was low in omega- 6 fatty acids. After 3.5 years the group with the low omega- 6 fatty acid intake had $70 \%$ fewer fatal and nonfatal heart attacks and a complete elimination of sudden cardiac death compared to the group following the high omega- 6 fatty acid diet.

The impact of a high omega- 6 fatty acid diet can be understood from the metabolic pathway of linoleic acid conversion to AA as shown in Figure 1.

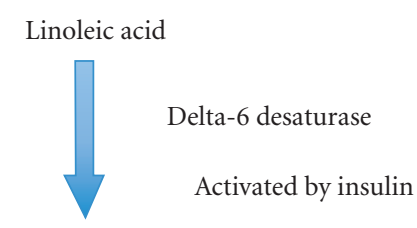

Gamma linolenic acid

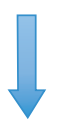

Dihomo gamma linolenic acid

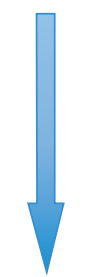

Delta-5 desaturase

Activated by insulin

Inhibited by EPA

Arachidonic acid (AA)

Figure 1: Metabolism of Omega-6 Fatty Acids.

The two rate-limiting steps in this metabolic cascade of linoleic acid to arachidonic acid are the enzymes delta6 and delta-5 desaturase. These enzymes insert cis-double bonds into unique positions in the omega- 6 fatty acid molecule. Normally, these steps are very slow, thus limiting the production of AA. However, insulin is a strong activator of each of these enzymes [27-30]. This means that a high glycemic-load diet coupled with increased intake of vegetable oils rich in linoleic acid will lead to increased production of $\mathrm{AA}$ and a corresponding increase in silent inflammation.

Finally, there is the role of the omega- 3 fatty acid EPA in this metabolic cascade and its effect on silent inflammation. In high enough concentrations, EPA can partially inhibit the activity of the delta-5-desaturase enzyme thus reducing AA formation by acting as a weak feedback inhibitor as both fatty acids use the same enzyme for their production. More importantly, an increased EPA content in the membrane phospholipids decreases the release of AA that is necessary to make pro-inflammatory eicosanoids. In this regard, increased consumption of EPA dilutes out existing $\mathrm{AA}$, thus decreasing the production of pro-inflammatory eicosanoids. Finally, EPA is the molecular building block to powerful anti-inflammatory eicosanoids known as resolvins [31-34].

Unfortunately, the consumption of long-chain omega-3 fatty acids, such as EPA, has dramatically decreased over the past century [35]. With that decrease in EPA intake coupled with the increased consumption of refined carbohydrates and vegetable oils, the dietary stage was set for a dramatic increase in silent inflammation. 


\section{How Obesity Induces Chronic Disease}

Obesity can be defined as accumulation of excess body fat. However, it is the location of that excess body fat that determines whether or not obesity leads to acceleration of chronic diseases. If the extra body fat is constrained to the adipose tissue and there is no compromise of metabolic function, that obese individual would be considered metabolically healthy [36]. Apparently $1 / 3$ of obese Americans fall into this category [37]. On the other hand, if increasing amounts of the excess fat become deposited in other organs (muscles, cardiac tissue, liver, pancreas), this is known as lipotoxicity [3840]. With lipotoxicity comes an acceleration of those chronic diseases (diabetes, heart disease, cancer, etc.) associated with obesity. The extent of lipotoxicity will be determined by the health of the fat cells in the adipose tissue.

\section{Adipose Tissue as a Staging Area for Systemic Silent Inflammation}

The adipose tissue is the only organ in the body that can safely store triglycerides. As a consequence, it occupies the central position in controlling silent inflammation by acting as a fat-buffering system especially by controlling the blood levels of AA. Healthy fat cells have the ability to extract any excess fatty acid (including AA) in the blood and to safely store it as a triglyceride. In addition, the adipose tissue can readily induce the formation of new fat cells from internal stem cells to increase the storage of increasing levels of circulating fat in blood coming from either ingestion of dietary fat or metabolism of excess carbohydrates and protein that have been converted into circulating fat by the liver [41].

\section{Fat Cell Life Cycle}

The definition of a healthy fat cell is one that can easily expand to sequester incoming fats, in particular, for longterm storage, and also governs the controlled release of stored fat for ATP production in the peripheral tissues. The ability to sequester circulating fat into the fat cell depends upon the integrity of insulin signaling that brings adequate levels of glucose into the fat cell that can be converted to glycerol. This necessary step is required to convert incoming free fatty acids into triglycerides for long-term storage.

The problem begins to arise when AA levels become too great in a particular fat cell. As an initial defensive mechanism, the generation of new fat cells is induced by metabolites of AA [42, 43]. Although this is associated with greater adiposity [44], the creation of new healthy fat cells maintains the capacity of the adipose tissue to prevent potential lipotoxicity. However, as the AA levels continue to increase in any particular fat cell, the cell's response to insulin signaling becomes compromised due to internal silent inflammation that interrupts the flow of glucose into the fat cell to provide the necessary glycerol for fatty acid storage [45]. It appears this is a consequence of the generation of pro-inflammatory eicosanoids (leukotrienes) that are derived from AA $[46,47]$. As a result, the fat cell has a more difficult time sequestering newly formed AA as well as other fatty acids circulating in the blood. At the same time, insulin inhibition of the hormone-sensitive lipase in that particular fat cell becomes compromised because of the same disruption in the insulin-signaling cascade. As a result, more free fatty acids are being released into circulation [48, 49]. These are the hallmarks of classical insulin resistance. It appears that insulin resistance due to increased AA levels may arise in the fat cell prior to developing in the muscle cells $[50,51]$. As a result, greater amounts of AA remain in circulation to be taken up by other cells potentially leading to acceleration of insulin resistance in the muscle cells, which in turn causes increased hyperinsulinemia. To further compound the situation, a compromised fat cell is releasing greater amounts of previously sequestered AA in the fat cells into the circulation [52].

As the levels of AA further increase in any one particular fat cell beyond a critical threshold barrier, cell death can take place [53]. The necrosis of that particular fat cell causes a migration of macrophages into the adipose tissue $[54,55]$. This increase in macrophage accumulation in the adipose tissue is clearly seen in both animal models of obesity as well as in humans [56]. These newly recruited macrophages cause the secretion of additional inflammatory mediators, such as IL-1, IL-6 and TNF $\alpha$, which increase inflammation within the adipose tissue [57-69]. These newly released inflammatory cytokines can interact with their receptors at the surface of nearby fat cells to signal a further activation of $N F-\kappa B$, the key gene transcription factor that drives the inflammatory responses of the innate immune system. Support for this hypothesis of AA-driven inflammation in the fat cells comes from the observations that the amount of macrophage accumulation can be significantly reduced upon supplementation with high-dose fish oil rich in EPA to reduce the inflammation in the adipose tissue [70-72].

As inflammation in the adipose tissue increases, inflammatory cytokines, such as IL-6 derived from the macrophages attracted to the inflamed fat cells, can exit into the circulatory system to cause an increase in CRP formation in the liver. Hence the correlation between obesity and CRP levels [73]. Likewise TNF $\alpha$ generated by the same macrophages causes further insulin resistance in the surrounding fat cells, thus decreasing their ability to sequester newly formed $\mathrm{AA}$ as well as causing the release of even more stored AA into the circulatory system. In many ways, the staging area for insulin resistance in other organs (muscles, liver, and eventually the pancreas) can be considered to start in the adipose tissue. As insulin resistance spreads to other organs, the end result is lipotoxicity in the muscle cells (both smooth muscle and cardiac muscle), liver, and the beta cells in the pancreas.

As long as the adipose tissue is composed of healthy fat cells, any increased production of dietary-induced AA can be safely handled by their continued expansion that can rapidly remove any excess AA from the blood and store it safely in the fat cells. In the absence of a large percentage of healthy fat cells in the adipose tissue, the combination of the growing lack of ability to sequester AA from the blood coupled with 
the accelerated release of stored AA from the fat mass into the circulation is similar to the metastatic spread of a tumor; only now it is silent inflammation that is spreading. Depositions of lipid droplets that cause lipotoxicity characterize this metastasis of silent inflammation. If these accumulated lipid droplets are also enriched in AA, then the development of inflammatory diseases, such as type 2 diabetes, will be accelerated.

Understanding the role of healthy fat cells may explain why approximately one-third of obese individuals are actually quite healthy [37]. These individuals appear to have higher levels of the adipose-derived hormone adiponectin [74]. This is confirmed by studies of the overexpression of adiponectin in diabetic animals [75]. It should be noted that adiponectin is an adipose-derived hormone that can be increased by high levels of fish oil rich in EPA possibly acting through the PPAR $\gamma$ transcription factor [76-78].

One of the first indications that lipotoxicity is taking place is the appearance of metabolic syndrome. Metabolic syndrome can be considered to be prediabetes. It is characterized by a combination of clinical markers, such as a high TG/HDL ratio, increasing abdominal fat, and hyperinsulinemia. Recent data indicate that there is a strong correlation between metabolic syndrome and levels of AA in the adipose tissue [50].

Left untreated, metabolic syndrome will usually result in the development of type 2 diabetes within $8-10$ years. During this time period, the insulin resistance of the individual is continually increasing. This will cause even more AA formation, especially if consumption of omega- 6 fatty acids remains high. Since the fat cells are now compromised in their ability to sequester this increased AA production, the AA levels remain in the blood to be picked up by other organs.

The final development of type 2 diabetes only occurs when the lipotoxicity has metastasized to the pancreas, causing a decreased output of insulin [79]. With insulin secretion decreased, there is a rapid rise of blood sugar levels. The development of type 2 diabetes indicates that the metastasis of silent inflammation from the adipose tissue to the pancreas is now complete.

Ironically, even extreme lipotoxicity can be reversed by the creation of new healthy fat cells. This has been demonstrated in transgenic obese, diabetic mice that overexpress adiponectin, an adipocyte-derived hormone that reduces insulin resistance [75]. It is hypothesized that this increased production of adiponectin activates PPAR $\gamma$, which causes the proliferation of adipose stem cells to produce new healthy adipocytes. These transgenetic obese mice become even more obese, but there is a normalization of blood glucose and lipid levels [75]. This is similar to the elevated levels of adiponectin found in metabolically healthy obese individuals [74]. One mechanism of protection against lipotoxicity might be that the new healthy fat cells in the adipose tissue can now sequester circulating fatty acids (including AA) more effectively to allow the resolution of the inflammatory lipid droplets in the muscle, liver and beta cells of the panaceas. Essentially this resolution process represents a reverse flow of the lipotoxic lipid droplets in other organs back to the adipose tissue and reverses insulin resistance in the muscle and liver cells as well as decreasing the inflammation in the beta cells of the pancreas.

Support of this hypothesis regarding the impact of AA on fat cell metabolism comes from studies on AA levels in fat cells on various chronic disease conditions. In particular, increased AA levels in the fat cells are significantly associated with increased body fat, development of metabolic syndrome, and incidence of nonfatal heart attacks $[44,50$, $80]$.

\section{Anti-Inflammatory Nutrition}

The goal of anti-inflammatory nutrition is to understand how pharmacological targets of inflammation can also be impacted by dietary nutrients. This would include reduction of those dietary components (a) that directly activate the inflammatory responses of innate immune system that directly affecting gene transcription factors such as NF$\kappa \mathrm{B}$ or (b) that indirectly activate $\mathrm{NF}-\kappa \mathrm{B}$ by interacting with toll-like receptors or cytokine receptors. These dietary nutrients that induce an inflammatory response can disrupt hormonal signaling patterns between hormone receptors and their internal targets giving rise to insulin and leptin resistance. These dietary nutrients (AA and saturated fats) that induce inflammatory responses via $\mathrm{NF}-\kappa \mathrm{B}$ are ones that must be significantly reduced in the diet. Other dietary components (such as omega-3 fatty acids and polyphenols) that either inhibit toll-like receptors or activate antiinflammatory gene transcription factors such as $\operatorname{PPAR} \alpha$ and PPAR $\gamma$ must be increased to therapeutic levels in the diet. The combination of these two dietary strategies should lead to a comprehensive inflammatory gene silencing technology.

Before discussing these molecular targets in detail in the context of anti-inflammatory nutrition, it is best to start with our knowledge of the molecular targets in terms of current anti-inflammatory pharmacological approaches used today especially in the treatment of obesity and diabetes.

\section{Pharmacological Targets for Reducing Inflammation}

12.1. Anti-Inflammatory Drug Targets. If the hypothesis is correct that obesity is caused by silent inflammation, then modulating molecular targets of anti-inflammatory drugs would hold promise. Anti-inflammatory drugs remain the foundation of medical treatment of pain caused by acute inflammation. The relief of acute pain requires immediate action with drugs. The more acute the pain, the more powerful the anti-inflammatory drug that has to be used. Unfortunately, the more powerful the anti-inflammatory drug, the greater the side effects. Our working hypothesis is that the obesity and the metabolic consequences of obesity are caused by chronic low-level inflammation or silent inflammation. Nonetheless the molecular targets of antiinflammatory drugs are the same for anti-inflammatory nutrition. 
The classical pathways of anti-inflammatory drugs have been focused on the COX and LOX pathways of eicosanoid production. Inhibitors of the COX enzymes, such as aspirin and nonsteroidal anti-inflammatory drugs (NSAIDs), have different targets. Aspirin is a suicide inhibitor of the $\mathrm{PGH}_{2}$ synthase enzyme that is the rate-limiting step of the formation of pro-inflammatory eicosanoids. NSAIDs, on the other hand, are competitive inhibitors of various enzymes involved in the generation of pro-inflammatory prostaglandins. However, neither of these drugs has much effect on the LOX pathways that generates leukotrienes. Corticosteroids inhibit both the COX and LOX pathways by inhibiting the release of AA from the phospholipids in the cell's membranes.

12.2. Gene Transcription Factor Targets. The key component of the inflammatory response is the activation of NF- $\kappa \mathrm{B}$, which acts as master genetic switch to cause the express of inflammatory proteins (such as the COX-2 enzyme and various inflammatory cytokines) that amplifies the inflammatory response. Recent evidence has indicated that aspirin, salicylates, and statins also inhibit the activation of NF- $\kappa \mathrm{B}$ at high concentrations $[11,12]$. It is now hypothesized that many of the cardiovascular benefits of statins may come from their anti-inflammatory actions as opposed to their cholesterol-lowering effects [81].

If NF- $\kappa \mathrm{B}$ can be considered to be an inflammatory gene transcription factor, then the PPAR family of gene transcription factors can be considered to be anti-inflammatory. There are a number of drugs that activate the PPAR systems. PPAR $\alpha$ is the transcription factor that induces the increased expression of fat oxidation enzymes. It is this transcription factor that is activated by drugs such as fibrates [82]. These drugs are effective in lowering triglyceride levels and are widely used in cardiovascular treatment. Once the PPAR $\gamma$ system is activated, it has profound anti-inflammatory effects including the generation of new healthy fat cells that reduce lipotoxicity. The thiazolidinediones, a mainstay of diabetes treatment, are examples of such drugs that activate the PPAR $y$ gene transcription factor [83]. However unlike omega-3 fatty acids, thiazolidinediones do not have a protective effect against heart attack [84]. In fact, one of the more commercially successful thiazolidinediones (i.e., rosiglitazone) has been implicated in increased cardiovascular events [85].

12.3. Regulatory Enzyme Targets. Certain enzymes act as energy sensors and can regulate a great number of metabolic systems especially dealing with glucose and lipid metabolism, especially AMP kinase. The diabetic drug metformin is one such drug that activates this particular enzyme $[86,87]$. This enzyme not only generates adequate levels of ATP, but also regulates a wide number of enzyme systems involved in glucose and lipid metabolism [88]. As a result, metformin is sometimes used as an off-label weight loss drug [89].

12.4. Hormone Targets. Obviously, the most important hormones in this category are the eicosanoids derived from
AA described earlier. Another group of hormones derived from AA include endocannabinoids that are involved in generating hunger. The endocannabinoid receptor antagonist (rimonabant) was developed as an appetite-suppressant for the treatment of obesity [90]. This drug was never approved in the United States due to its various neurological problems, including an increase in suicidal tendencies. These problems far overshadowed any potential weight loss benefits.

Other hormones involved in the appetite control come from the gut, including the satiety hormones PYY and GLP1. Currently the only long-term medical intervention to treat obesity is gastric bypass surgery. The most successful of these types of surgery is Roux-en-Y gastric bypass that reroutes much of the small intestine thus delivering most of the dietary nutrients to the distal part of the small intestine (i.e., ileum). Unlike other gastric bypass methods, this surgery also increases the release of gut hormones such as PYY and GLP-1 from the L-cells in the ileum, to give a profound degree of satiety [91]. This has led many drug companies to test various drugs to increase satiety hormones in order to achieve the same weight loss benefits of Rous-en-Y bypass surgery. Two diabetic drugs, exenatide (a GLP-1 receptor agonist) and sitagliptin (an inhibitor of the enzyme that degrades GLP-1) have demonstrated the potential for inducing weight loss. Combination products consisting of hormones such as pramlinitide and leptin are in various stages of testing, but have not yet been approved.

12.5. Neurotransmitter Targets. Although we have many successful examples of drugs for the treatment of acute inflammation, cardiovascular, and diabetes, there are relatively few examples of drugs that are very successful in the treatment of obesity. The most successful of these drugs are amphetamines that stimulate dopamine receptors in the brain leading to increased satiety. Unfortunately, they can also lead to addiction [92]. It was though a combination drug known as fen-phen that might circumvent this problem. Fenphen was a combination of a weaker amphetamine (phentermine) and a powerful serotonin agonist (fenfluramine). This drug combination was dropped then, it was discovered that it increased the incidence of primary pulmonary hypertension and heart valve degeneration [93]. A new combination of phentermine and the antiepilepsy drug topiramate is under investigation, but has not yet been approved.

Phentermine and other ampthetamine derivatives are still in use today for the treatment of obesity but only for short-term use (approximately 12 weeks). In an effort to bypass these restrictions, various amphetamine-like drugs used to treat attention-deficient conditions are often used as off-label weight loss drugs.

The only currently approved drugs for long-term treatment of obesity are sibutramine (i.e., structurally similar to amphetamines) that acts as serotonin and norepinephrine reuptake inhibitor and orlistat that inhibits the breakdown of fat in the GI tract. Unfortunately, neither of these drugs has demonstrated any significant impact in reversing the obesity epidemic. 


\section{Molecular Targets for an Anti-Inflammatory Nutrition}

With the above as a short review of the pharmacological targets for reducing inflammation or treating obesity, we can now turn to understanding how various dietary components can be used to interact with the same molecular targets as pharmacological agents.

13.1. Pro-Inflammatory Nutrients. Anti-inflammatory drugs work by inhibiting the formation of downstream proinflammatory eicosanoids derived from AA. A more elegant approach is to go upstream and reduce the levels of AA in the cells thereby reducing the substrate required for the production of pro-inflammatory eicosanoids. There is no known drug that can reduce AA. Only the diet can $[94,95]$. The most obvious solution is the reduction of the direct dietary intake of AA. Dietary sources richest in AA include organ meats and egg yolks. Other food sources that are slightly lower in AA content include all animal protein sources including fish. It has also been shown that AA has a direct effect on the activation of NF- $\kappa$ B [96]. This may be mediated by increased leukotriene production $[46,47]$.

However, even if individuals were following even a strict vegetarian diet, they would be able to produce large amounts of AA if that vegetarian diet is rich in both omega- 6 fatty acids and high glycemic index carbohydrates that stimulate insulin secretion. As described earlier, the combination of these two dietary factors will increase the production of AA. Therefore in addition to reducing the direct intake of AA, one should also have dietary strategy for the simultaneous reduction of the dietary intake of omega- 6 fatty acids, such as linoleic acid, and lowering of the levels of insulin generated by the diet. Reduction of linoleic acid can be achieved by using fat sources low in omega- 6 fatty acids, such as olive oil or nuts as well as reducing the consumption of red meat. Reducing insulin requires a reduction of the glycemic load of the diet by increasing the consumption of vegetables and fruits as the primary sources of carbohydrates and the simultaneous reduction of the consumption of highglycemic carbohydrates, such as grains and starches. Another inflammatory nutrient is saturated fatty acids. Saturated fats can bind to TLR-4 and thus indirectly activate NF- $\kappa$ B [97102].

Finally, what is often not appreciated is that the total calorie content of a meal can also raise insulin levels and increase inflammation. Therefore maintaining a calorierestricted diet is also essential for insulin control. It has been demonstrated that overnutrition causes inflammation in the hypothalamus and disrupts the precise signaling balance of satiety and hunger hormones and thus increases appetite [103].

13.2. Anti-Inflammatory Nutrients. The omega-3 fatty acid eicosapentaenoic acid (EPA) will have little direct impact on the reduction of AA because it is a weak inhibitor of the delta 5-desaturase enzyme; however, at high dietary intakes, the EPA can dilute out the concentration of AA in the cell membrane thereby decreasing its potential of being converted into a pro-inflammatory eicosanoids, such as leukotrienes. As stated earlier, high intakes of EPA can also reduce inflammation in the adipose tissue [70-72]. Thus by either directly inhibiting the formation of AA or diluting it out by the presence of high levels of EPA in target cells (especially in the adipose tissue), overall inflammation will be automatically reduced as long there is constant supplementation with fish oils rich in EPA.

13.3. Gene Transcription Factors. Inhibition of the NF- $\kappa \mathrm{B}$ is another key anti-inflammatory nutrient target. AA can directly activate NF- $\kappa \mathrm{B}$ [96] or serve as substrate for the production of leukotrienes that also appear to activate NF$\kappa \mathrm{B}[46,47]$. Thus, the overall reduction of AA will not only reduce the production of pro-inflammatory eicosanoids, but also inhibit the release of gene products (COX-2 enzymes and inflammatory cytokines such as TNF $\alpha$, IL-1, and IL-6) that are expressed if NF- $\kappa \mathrm{B}$ is activated.

Omega-3 fatty acids and polyphenols can also inhibit the activation of NF- $\kappa \mathrm{B}[104,105]$. However, one requires a therapeutic level of these nutrients to have any significant inhibition of NF- $\kappa$ B. Omega- 3 fatty acids can also inhibit the binding of saturated fats to the TLR-4 on the cell surface thus also indirectly inhibiting NF- $\kappa$ B activation [106].

PPAR $\alpha$ is the gene transcription factor activated by fibrates thus increasing the expression of fat oxidation enzymes needed to lower triglyceride levels. The same transcription factor can be activated by omega- 3 fatty acids, such as EPA and docosahexaenoic acid (DHA). Both omega3 fatty acids appear to provide a similar activation of this gene transcription factor [107]. By reducing the circulating levels of triglycerides, one also reduces the potential development of lipotoxicity. In essence, one is using fat (if it is rich in EPA and DHA) to burn fat by activating PPAR $\alpha$.

PPAR $\gamma$ is anti-inflammatory gene transcription factor. Its activation creates the stimulus for the production of new healthy fat cells that enhance the capacity of the adipose tissue for resequestering accumulated fat in other tissues thus reversing lipotoxicity. This will reverse much of the metabolic damage caused by the lipotoxicity, but it may possibily make the individual fatter in the process. PPAR $\gamma$ is stimulated by adiponectin whose release from fat cells can be enhanced by the increased consumption of omega-3 fatty acids [76-78]. In addition, EPA and DHA can also directly activate PPAR $\gamma$ [108].

13.4. Hormones. Many of the hormones involved in the control of hunger and satiety are generated by diet. Insulin is a key hormone in the development of obesity. If insulin levels remain elevated, the stored fat in the adipose tissue will remain sequestered due to its inhibition of the hormone sensitive lipase in healthy fat cells. In addition, insulin in the blood is a hunger hormone because of its ability to lower blood glucose levels. Although a diet rich in highglycemic carbohydrates will increase the post-prandial levels of insulin, hyperinsulinemia caused by silent inflammation in the muscle cells will keep insulin constantly elevated. 
This sets up a cycle of increased calorie (primarily carbohydrate) consumption generating increased inflammation in the hypothalamus that dissociates hunger and satiety signals [103].

Ironically, insulin can also function as a satiety hormone if it can reach the hypothalamus [109-111]. But if one has insulin resistance (induced by silent inflammation), then the high levels of insulin in the blood are unable to relay their message to the key cells in the hypothalamus and potential satiety effects of insulin are blunted. Leptin is a hormone released from the fat cells that is also involved in satiety. Like insulin, it must also reach the hypothalamus to exert its satiety actions. Obese individuals are characterized by both insulin and leptin resistance [110-113].

Inhibition of endocannabinoid binding to its receptors in the brain is the mechanism action of rimonabant. Since endocannabinoids are derived from AA, reduction of its levels in the brain should reduce hunger. Unfortunately, the half-life of AA in the brain is long in humans [114]. However, increasing the levels of EPA in the brain can inhibit the binding of endocannabinoids [115]. Since the half-life of EPA in the brain appears to be very short [116], this requires maintaining a therapeutic level of EPA in the blood to create a constant gradient necessary for the constant flow of the EPA into the brain. This gradient can only be maintained by a diet either very high in fatty fish consumption or supplemented by fish oil rich in EPA.

As mentioned earlier, much of the success of gastric bypass surgery is related to the increase in satiety hormones (PYY and GLP-1) released from the ileum. The release of these hormones can be enhanced by slowing down the rate of digestion and absorption of protein and carbohydrate in a meal so that greater amounts of these nutrients can reach the L-cells in the ileum. Lowering the glycemic load of the diet by the inclusion of fiber-rich carbohydrate sources (especially those rich in soluble fiber) can slow the digestion and absorption process of both protein and carbohydrate. At the same time, increasing the protein content of that meal will also increase PYY levels [117]. The slower rates of digestion and absorption mean more of these hormone agonists will appear in the ileum and thus generate higher levels of these satiety hormones.

13.5. Neurotransmitters. Amphetamines increase dopamine levels and decrease hunger [92]. EPA and DHA can also increase dopamine levels in animal models [118]. It has been demonstrated that dietary supplementation of highdose EPA and DHA can further reduce the symptoms of attention-deficit hyperactivity disorder (ADHD) in children already on their optimal level of drugs used to treat this condition $[119,120]$.

13.6. AMP Kinase. This particular enzyme is stimulated by metformin $[86,87]$. High levels of polyphenols can also stimulate the same enzyme [121-123]. Its activation is a key for not only increasing ATP levels, but also to regulate lipid and carbohydrate metabolism. As with EPA, therapeutic levels of polyphenols are required due to their low bioavailability probably due to their rapid degradation in the small intestine.

13.7. Increased Thermogenesis. The higher the protein content of the diet is, the more thermogenesis is increased $[124,125]$. The underlying cause may be activation of protein synthesis. To activate such protein synthesis requires a combination of adequate levels of leucine and a consistent level of insulin in the blood to activate mTOR to stimulate protein synthesis during the post-prandial period [126]. Data suggest that it takes 20-30 grams of protein at a meal to stimulate this protein synthesis [127].

\section{Developing an Anti-Inflammatory Diet Based on Anti-Inflammatory Nutrition}

Anti-inflammatory nutrition is the understanding how individual nutrients affect the same molecular targets affected by pharmacological drugs. This is only the first step in developing an anti-inflammatory diet. Such a diet should contain all nutrient considerations described above, as well as being a diet that can promote compliance for a lifetime.

The first question would concern the protein, carbohydrate, and fat composition for such an anti-inflammatory diet. Currently the dietary recommendations for suggested fat content in diet range from 20 to $35 \%$ of total calories [128]. Lower-fat diets are simply too difficult to maintain for a sustained basis as demonstrated in long-term studies [129131]. Therefore long-term dietary compliance appears to be more likely at $30 \%$ of total calories as dietary fat. However, the fat composition must also be low in both omega- 6 and saturated fats because of their ability to increase silent inflammation by their interaction with various components of the innate immune system. The only common dietary fats that are low in both omega- 6 and saturated fats are olive oil and nuts. Thus they should constitute the bulk of the dietary fat in any anti-inflammatory diet.

The next question is the amount of protein. Most dieticians would recommend consumption of no more lowfat protein than would fit on the palm of your hand. This translates into about $3 \mathrm{oz}$. of a low-fat protein source (this would contain about 20 grams of amino acids) for a typical female and approximately $4 \mathrm{oz}$. of low-fat protein (this would about 30 grams of amino acids) for a typical male. These traditional dietary recommendations are supported by recent research that indicates that this level of high-quality protein will contain enough of the branched-chain amino acid leucine to initiate protein synthesis [132]. Furthermore the absolute intake of protein should be between 20-30 grams at every meal to activate protein synthesis to increase thermogenesis $[124,127,132]$. If one takes into account the protein content of carbohydrate sources and potential snacks, then the average female should be consuming about 80-90 grams of low-fat protein per day and the average male about 100-110 grams of low-fat protein per day. This amount of protein would have to be equally spaced at each meal to provide the necessary levels of protein for 
the enhanced release of PYY from the L-cells in the ileum after each meal thereby controlling satiety.

The carbohydrate content should be able to maintain a stable level of insulin between meals. This can be achieved with about 40 grams of low glycemic load carbohydrates at each meal. The vast bulk of the carbohydrates should come from sources with the highest content of polyphenols with the least amount of carbohydrates, meaning the consumption of primarily colorful nonstarchy vegetables, moderate amounts of fruits, limited amounts of wholegrains, and a radical reduction of the dietary intake of refined carbohydrates. Although there is some controversy to whether a low glycemic load diet leads to improved weight loss $[133,134]$, there is no question that a low glycemic load diet will generate a lower inflammatory burden [135137].

Finally, there is the question of meal timing. The hormonal control benefits of any meal will last only about five hours. To achieve this hormonal control would require three low-calorie meals and two even lower-calorie snacks spaced throughout the day so that five hours never pass before consuming another meal or snack.

Such a proposed anti-inflammatory diet would consist of about 1,500 calories per day (about 50 grams of monounsaturated fat, 100 grams of low-fat protein, and 150 grams of low glycemic load carbohydrates per day). This would represent a $1: 2: 3$ ratio of fat to protein to carbohydrate on a weight basis. On a calorie basis, that is about $30 \%$ of the calories as fat, $30 \%$ as protein, and $40 \%$ as carbohydrates. These are the dietary recommendations made by one of the authors in 1995 [94]. Similar dietary recommendations were made by the Joslin Diabetes Research Center at Harvard Medical School for the treatment of obesity, metabolic syndrome, and diabetes in 2005 [138] and confirmed by their own pilot studies [139]. It should be noted that we believe total calorie consumption should be driven by protein requirements necessary to maintain a positive nitrogen balance of essential amino acids, such as leucine. As an example, a typical female might require a total of 90 grams of protein per day to maintain adequate leucine levels to stimulate protein synthesis, whereas a male might require 110 grams of total protein per day. Thus using the macronutrient balance described above, the typical female would require slightly more than 1300 calories per day, whereas the typical male would require about 1600 calories per day to generate enough chemical energy for daily metabolic needs. Obviously, higher levels of physical activity in either the female or male would require higher protein intake to compensate for the breakdown of muscle protein during exercise with a corresponding increase in total calorie consumption [140].

To this anti-inflammatory diet foundation should be added supplemental omega-3 fatty acids at the level of 23 grams of EPA and DHA per day either by an increased consumption of fatty fish or supplementation with fish oil supplements rich in EPA. Finally, a diet rich in colorful, nonstarchy vegetables also would contribute adequate amounts of polyphenols to help not only to inhibit NF- $\kappa \mathrm{B}$, but also activate AMP kinase.
In many respects, this proposed anti-inflammatory diet has similarities to a Mediterranean diet. Both are rich in vegetables and fruits. Both emphasize the moderate intake of low-fat protein sources, such as chicken and fish. Both recommend the use of monounsaturated fats, like olive oil and nuts. The differences are in the carbohydrate composition. An anti-inflammatory diet radically restricts the use of bread and grains (especially refined grain products) and makes up for it with increased consumption of more colorful (i.e., rich in polyphenols) vegetables and fruits. That one seemingly small difference will have tremendous hormonal and genetic consequences leading to a lowered inflammatory burden.

The goal of an anti-inflammatory diet is not weight loss per se, but the reduction of silent inflammation. Of course, this same reduction of silent inflammation should also result in consistent fat loss if our working hypothesis is correct that silent inflammation is a driving force for the accumulation of body fat. This is accomplished by affecting the same molecular targets that have been elucidated by pharmacological agents. The success of this anti-inflammatory diet can be measured clinically by various markers of silent inflammation as mentioned earlier as well as improvement of metabolic conditions (i.e., metabolic syndrome, diabetes, cardiovascular disease, etc.) that are associated with obesity.

\section{Why Not Simply Eat Less and Exercise More?}

Obesity is far more complex than simply it is caused by calories in being greater than calories out. This is why just telling obese individuals to eat less and exercise will rarely work. Obesity is a metabolic condition in which affects those who are genetically predisposed. Any increase in silent inflammation will cause disruption in metabolic use of fat coming from the adipose tissue to make adequate levels of ATP and also cause a dissociation of hunger and satiety signals in the brain. The combination will leave the obese individual constantly hungry and thus seeking food. Our working hypothesis is that the increased levels of silent inflammation generated by the diet cause a disruption in the signaling mechanisms in both the adipose tissue and the hypothalamus that leads to the accumulation of excess body fat. Unless those inflammatory driving forces are consistently reduced by the diet, the success rate for obese individuals trying to "eat less and exercise more" will remain abysmal.

This is perhaps best demonstrated by the data derived from the National Weight Control Registry on individuals who have lost considerable amounts of weight and have kept it off for more than five years [141, 142]. The average calorie intake for these individuals is approximately than 1,400 calories per day, which is in agreement with our general caloric recommendations. Although the National Weight Control Registry represents a biased reporting population, it is indicative that our suggested calorie intake is in line with long-term weight maintenance as long as our recommended protein amounts are being consumed on a consistent basis throughout the day. It should also be noted that these individuals also exercise for approximately one hour per day which would increase their protein and calorie requirements. 
This suggests that our calorie recommendations for sedentary individuals may actually be generous.

Implementation of an anti-inflammatory diet would reduce the silent inflammation that will make it easier to not only maintain a reduced weight with less effort, but also markedly reverse the driving force (i.e., lipotoxicity) for the development of chronic disease. That is the real reason to lose excess body fat.

\section{Summary}

The ultimate treatment of obesity lies in re-establishing hormonal and genetic balance that generates satiety instead of constant hunger. This can be achieved by reducing silent inflammation induced by the diet. Pharmacological agents can pinpoint what those molecular targets are that induce inflammation. The purpose of anti-inflammatory nutrition is to determine which food ingredients can affect the same molecular targets as drugs and determine what the therapeutic concentrations are for those nutrients required to affect the same molecular targets. Only then can you develop an anti-inflammatory diet that has to be used like a drug at the right time and right level to keep silent inflammation under control.

Obesity is not a consequence of a drug deficiency or a lack of will power, but a lack of knowledge of which nutrients are necessary and which concentrations that are required to control silent inflammation and therefore control appetite. Silent inflammation is generated by the mismatch of our current diet and our genes. Anti-inflammatory nutrition should be considered as a form of gene silencing technology, in particular the silencing of the genes involved in the generation of silent inflammation. Pharmacological agents often work downstream from the true primary molecular target of inflammation $(\mathrm{NF}-\kappa \mathrm{B})$, whereas anti-inflammation nutrition works upstream to reduce the dietary factors that activate $\mathrm{NF}-\kappa \mathrm{B}$ to generate silent inflammation. Not only is upstream targeting a more elegant way to treat obesity with an almost infinite therapeutic index compared to pharmacological agents, but it also provides a new approach to treat chronic diseases ultimately caused by silent inflammation.

\section{Financial Disclosures}

Barry Sears is the Chairman of Zone Labs, Inc. and MedWell Foods, Inc.

\section{References}

[1] V. Vachharajani and D. N. Granger, "Adipose tissue: a motor for the inflammation associated with obesity," IUBMB life, vol. 61, no. 4, pp. 424-430, 2009.

[2] J. M. Olefsky, "IKKe: a bridge between obesity and inflammation," Cell, vol. 138, no. 5, pp. 834-836, 2009.

[3] K. E. Wellen and G. S. Hotamisligil, "Obesity-induced inflammatory changes in adipose tissue," Journal of Clinical Investigation, vol. 112, no. 12, pp. 1785-1788, 2003.
[4] K. M. Flegal, M. D. Carroll, C. L. Ogden, and L. R. Curtin, "Prevalence and trends in obesity among US adults, 19992008," Journal of the American Medical Association, vol. 303, no. 3, pp. 235-241, 2010.

[5] C. N. Serhan, S. D. Brain, C. D. Buckley et al., "Resolution of inflammation: state of the art, definitions and terms," FASEB Journal, vol. 21, no. 2, pp. 325-332, 2007.

[6] C. N. Serhan, "Resolution phase of inflammation: novel endogenous anti-inflammatory and pro-resolving lipid mediators and pathways," Annual Review of Immunology, vol. 25, pp. 101-137, 2007.

[7] B Sears, OmegaRx Zone, Regan Books, New York, NY, USA, 2002.

[8] B. Sears, The Anti-Inflammation Zone, Regan Books, New York, NY, USA, 2005.

[9] B Sears, Toxic Fat, Regan Books, New York, NY, USA, 2008.

[10] G. S. Hotamisligil and E. Erbay, "Nutrient sensing and inflammation in metabolic diseases," Nature Reviews Immunology, vol. 8, no. 12, pp. 923-934, 2008.

[11] E. Kopp and S. Ghosh, "Inhibition of NF- $\kappa$ B by sodium salicylate and aspirin," Science, vol. 265, no. 5174, pp. 956959, 1994.

[12] H. Hölschermann, D. Schuster, B. Parviz, W. Haberbosch, H. Tillmanns, and H. Muth, "Statins prevent NF- $\kappa$ B transactivation independently of the IKK-pathway in human endothelial cells," Atherosclerosis, vol. 185, no. 2, pp. 240-245, 2006.

[13] A. R. Tall, "C-reactive protein reassessed," The New England Journal of Medicine, vol. 350, no. 14, pp. 1450-1452, 2004.

[14] B. Campbell, T. Badrick, R. Flatman, and D. Kanowski, "Limited clinical utility of high-sensitivity plasma C-reactive protein assays," Annals of Clinical Biochemistry, vol. 39, no. 2, pp. 85-88, 2002.

[15] B. Campbell, R. Flatman, T. Badrick et al., "Problems with high-sensitivity C-reactive protein," Clinical Chemistry, vol. 49, no. 1, pp. 201-202, 2003.

[16] D. J. A. Jenkins, T. M. S. Wolever, and R. H. Taylor, "Glycemic index of foods: a physiological basis for carbohydrate exchange," American Journal of Clinical Nutrition, vol. 34, no. 3, pp. 362-366, 1981.

[17] D. S. Ludwig, "The glycemic index: physiological mechanisms relating to obesity, diabetes, and cardiovascular disease," Journal of the American Medical Association, vol. 287, no. 18, pp. 2414-2423, 2002.

[18] A. Drewnowski and S. E. Specter, "Poverty and obesity: the role of energy density and energy costs," American Journal of Clinical Nutrition, vol. 79, no. 1, pp. 6-16, 2004.

[19] A. Drewnoswsi, A. S. Hanks, and T. G. Smith, Trade, Food, Diet, and Health, Wiley-Blackwell, West Sussex, UK, 2010.

[20] N. Darmon, M. Darmon, M. Maillot, and A. Drewnowski, "A nutrient density standard for vegetables and fruits: nutrients per calorie and nutrients per unit cost," Journal of the American Dietetic Association, vol. 105, no. 12, pp. 18811887, 2005.

[21] A. Drewnowski, N. Darmon, and A. Briend, "Replacing fats and sweets with vegetables and fruits-a question of cost," American Journal of Public Health, vol. 94, no. 9, pp. 15551559, 2004.

[22] P. Monsivais and A. Drewnowski, "The rising cost of low-energy-density foods," Journal of the American Dietetic Association, vol. 107, no. 12, pp. 2071-2076, 2007. 
[23] F. B. Hu, M. J. Stampfer, J. E. Manson et al., "Dietary fat intake and the risk of coronary heart disease in women," The New England Journal of Medicine, vol. 337, no. 21, pp. 14911499, 1997.

[24] W. C. Willett, "The role of dietary n-6 fatty acids in the prevention of cardiovascular disease," Journal of Cardiovascular Medicine, vol. 8, supplement 1, pp. S42-S45, 2007.

[25] M. de Lorgeril, S. Renaud, N. Mamelle et al., "Mediterranean alpha-linolenic acid-rich diet in secondary prevention of coronary heart disease," The Lancet, vol. 343, no. 8911, pp. 1454-1459, 1994.

[26] M. de Lorgeril, P. Salen, J.-L. Martin, I. Monjaud, J. Delaye, and N. Mamelle, "Mediterranean diet, traditional risk factors, and the rate of cardiovascular complications after myocardial infarction: final report of the Lyon Diet Heart Study," Circulation, vol. 99, no. 6, pp. 779-785, 1999.

[27] R. R. Brenner, "Nutritional and hormonal factors influencing desaturation of essential fatty acids," Progress in Lipid Research, vol. 20, no. 1, pp. 41-48, 1982.

[28] S. El Boustani, J. E. Causse, B. Descomps, L. Monnier, F. Mendy, and A. Crastes de Paulet, "Direct in vivo characterization of delta 5 desaturase activity in humans by deuterium labeling: effect of insulin," Metabolism, vol. 38, no. 4, pp. 315321, 1989.

[29] T. Pelikanova, M. Kohout, J. Base et al., "Effect of acute hyperinsulinemia on fatty acid composition of serum lipids in non-insulin-dependent diabetics and healthy men," Clinica Chimica Acta, vol. 203, no. 2-3, pp. 329-337, 1991.

[30] R. R. Brenner, "Hormonal modulation of $\delta-6$ and $\delta-5$ desaturases: case of diabetes," Prostaglandins Leukotrienes and Essential Fatty Acids, vol. 68, no. 2, pp. 151-162, 2003.

[31] C. N. Serhan, M. Arita, S. Hong, and K. Gotlinger, "Resolvins, docosatrienes, and neuroprotectins, novel omega-3-derived mediators, and their endogenous aspirin-triggered epimers," Lipids, vol. 39, no. 11, pp. 1125-1132, 2004.

[32] C. N. Serhan, "Novel $\omega$-3-derived local mediators in antiinflammation and resolution," Pharmacology and Therapeutics, vol. 105, no. 1, pp. 7-21, 2005.

[33] H. Seki, Y. Tani, and M. Arita, "Omega-3 PUFA derived antiinflammatory lipid mediator resolvin E1," Prostaglandins and Other Lipid Mediators, vol. 89, no. 3-4, pp. 126-130, 2009.

[34] H. Hasturk, A. Kantarci, E. Goguet-Surmenian et al., "Resolvin E1 regulates inflammation at the cellular and tissue level and restores tissue homeostasis in vivo," Journal of Immunology, vol. 179, no. 10, pp. 7021-7029, 2007.

[35] A. P. Simopoulos, "Essential fatty acids in health and chronic disease," American Journal of Clinical Nutrition, vol. 70, no. 3, supplement, pp. 560S-569S, 1999.

[36] A. D. Karelis, M. Faraj, J.-P. Bastard et al., "The metabolically healthy but obese individual presents a favorable inflammation profile," Journal of Clinical Endocrinology and Metabolism, vol. 90, no. 7, pp. 4145-4150, 2005.

[37] R. P. Wildman, P. Muntner, K. Reynolds et al., "The obese without cardiometabolic risk factor clustering and the normal weight with cardiometabolic risk factor clustering: prevalence and correlates of 2 phenotypes among the US population (NHANES 1999-2004)," Archives of Internal Medicine, vol. 168, no. 15, pp. 1617-1624, 2008.

[38] R. H. Unger, "Lipotoxic diseases," Annual Review of Medicine, vol. 53, pp. 319-336, 2002.

[39] R. H. Unger, "Weapons of lean body mass destruction: the role of ectopic lipids in the metabolic syndrome," Endocrinology, vol. 144, no. 12, pp. 5159-5165, 2003.
[40] R. H. Unger, G. O. Clark, P. E. Scherer, and L. Orci, "Lipid homeostasis, lipotoxicity and the metabolic syndrome," Biochimica et Biophysica Acta, vol. 1801, no. 3, pp. 209-214, 2010.

[41] S. Virtue and A. Vidal-Puig, "Adipose tissue expandability, lipotoxicity and the Metabolic Syndrome-an allostatic perspective," Biochimica et Biophysica Acta, vol. 1801, no. 3, pp. 338-349, 2010.

[42] F. Massiera, P. Saint-Marc, J. Seydoux et al., "Arachidonic acid and prostacyclin signaling promote adipose tissue development: a human health concern?" Journal of Lipid Research, vol. 44, no. 2, pp. 271-279, 2003.

[43] M. A. Mazid, A. A. Chowdhury, K. Nagao et al., "Endogenous 15 -deoxy- $\Delta 12,14$-prostaglandin J2 synthesized by adipocytes during maturation phase contributes to upregulation of fat storage," FEBS Letters, vol. 580, no. 30, pp. 6885-6890, 2006.

[44] S. C. Savva, C. Chadjigeorgiou, C. Hatzis et al., "Association of adipose tissue arachidonic acid content with BMI and overweight status in children from Cyprus and Crete," British Journal of Nutrition, vol. 91, no. 4, pp. 643-649, 2004.

[45] I. Talukdar, W. Szeszel-Fedorowicz, and L. M. Salati, "Arachidonic acid inhibits the insulin induction of glucose-6phosphate dehydrogenase via p38 MAP kinase," Journal of Biological Chemistry, vol. 280, no. 49, pp. 40660-40667, 2005.

[46] D. D. Sears, P. D. Miles, J. Chapman et al., "12/15lipoxygenase is equired for the early onset of high fat dietinduced adipose tissue inflammation and insulin resistance in mice," PLoS ONE, vol. 4, no. 9, Article ID e7250, 2009.

[47] S. K. Chakrabarti, B. K. Cole, Y. Wen, S. R. Keller, and J. L. Nadler, "12/15-lipoxygenase products induce inflammation and impair insulin signaling in 3T3-L1 adipocytes," Obesity, vol. 17, no. 9, pp. 1657-1663, 2009.

[48] L. M. Botion and A. Green, "Long-term regulation of lipolysis and hormone-sensitive lipase by insulin and glucose," Diabetes, vol. 48, no. 9, pp. 1691-1697, 1999.

[49] G. Haemmerle, R. Zimmermann, and R. Zechner, "Letting lipids go: hormone-sensitive lipase," Current Opinion in Lipidology, vol. 14, no. 3, pp. 289-297, 2003.

[50] E. S. Williams, A. Baylin, and H. Campos, "Adipose tissue arachidonic acid and the metabolic syndrome in Costa Rican adults," Clinical Nutrition, vol. 26, no. 4, pp. 474-482, 2007.

[51] L. Aldamiz-Echevarria, J. A. Prieto, F. Andrade, J. Elorz, P. Sanjurjo, and J. R. Soriano, "Arachidonic acid content in adipose tissue is associated with insulin resistance in healthy children," Journal of Pediatric Gastroenterology and Nutrition, vol. 44, no. 1, pp. 77-83, 2007.

[52] T. McLaughlin, A. Sherman, P. Tsao et al., "Enhanced proportion of small adipose cells in insulin-resistant vs insulin-sensitive obese individuals implicates impaired adipogenesis," Diabetologia, vol. 50, no. 8, pp. 1707-1715, 2007.

[53] C. Pompeia, T. Lima, and R. Curi, "Arachidonic acid cytotoxicity: can arachidonic acid be a physiological mediator of cell death?" Cell Biochemistry and Function, vol. 21, no. 2, pp. 97-104, 2003.

[54] S. P. Weisberg, D. McCann, M. Desai, M. Rosenbaum, R. L. Leibel, and A. W. Ferrante Jr., "Obesity is associated with macrophage accumulation in adipose tissue," Journal of Clinical Investigation, vol. 112, no. 12, pp. 1796-1808, 2003.

[55] H. Xu, G. T. Barnes, Q. Yang et al., "Chronic inflammation in fat plays a crucial role in the development of obesity-related insulin resistance," Journal of Clinical Investigation, vol. 112, no. 12, pp. 1821-1830, 2003. 
[56] E. Ortega Martinez de Victoria, X. Xu, J. Koska et al., "Macrophage content in subcutaneous adipose tissue: associations with adiposity, age, inflammatory markers, and wholebody insulin action in healthy pima Indians," Diabetes, vol. 58, no. 2, pp. 385-393, 2009.

[57] A. Festa, R. D’Agostino Jr., G. Howard, L. Mykkänen, R. P. Tracy, and S. M. Haffner, "Chronic subclinical inflammation as part of the insulin resistance syndrome: the insulin resistance atherosclerosis study (IRAS)," Circulation, vol. 102, no. 1, pp. 42-47, 2000.

[58] H. Ruan and H. F. Lodish, "Insulin resistance in adipose tissue: direct and indirect effects of tumor necrosis factor- $\alpha$," Cytokine and Growth Factor Reviews, vol. 14, no. 5, pp. 447455, 2003.

[59] P. A. Permana, C. Menge, and P. D. Reaven, "Macrophagesecreted factors induce adipocyte inflammation and insulin resistance," Biochemical and Biophysical Research Communications, vol. 341, no. 2, pp. 507-514, 2006.

[60] S. E. Shoelson, J. Lee, and A. B. Goldfine, "Inflammation and insulin resistance," Journal of Clinical Investigation, vol. 116, no. 7, pp. 1793-1801, 2006.

[61] J. G. Neels and J. M. Olefsky, "Inflamed fat: what starts the fire?" Journal of Clinical Investigation, vol. 116, no. 1, pp. 3335, 2006.

[62] S. Cinti, G. Mitchell, G. Barbatelli et al., "Adipocyte death defines macrophage localization and function in adipose tissue of obese mice and humans," Journal of Lipid Research, vol. 46, no. 11, pp. 2347-2355, 2005.

[63] Y.-H. Lee and R. E. Pratley, "The evolving role of inflammation in obesity and the metabolic syndrome," Current Diabetes Reports, vol. 5, no. 1, pp. 70-75, 2005.

[64] J. S. Yudkin, "Inflammation, obesity, and the metabolic syndrome," Hormone and Metabolic Research, vol. 39, no. 10, pp. 707-709, 2007.

[65] L. K. Heilbronn and L. V. Campbell, "Adipose tissue macrophages, low grade inflammation and insulin resistance in human obesity," Current Pharmaceutical Design, vol. 14, no. 12, pp. 1225-1230, 2008.

[66] C. de Luca and J. M. Olefsky, "Inflammation and insulin resistance," FEBS Letters, vol. 582, no. 1, pp. 97-105, 2008.

[67] U. Kintscher, M. Hartge, K. Hess et al., "T-lymphocyte infiltration in visceral adipose tissue: a primary event in adipose tissue inflammation and the development of obesitymediated insulin resistance," Arteriosclerosis, Thrombosis, and Vascular Biology, vol. 28, no. 7, pp. 1304-1310, 2008.

[68] S. E. Kahn, R. L. Hull, and K. M. Utzschneider, "Mechanisms linking obesity to insulin resistance and type 2 diabetes," Nature, vol. 444, no. 7121, pp. 840-846, 2007.

[69] J. A. Chavez and S. A. Summers, "Lipid oversupply, selective insulin resistance, and lipotoxicity: molecular mechanisms," Biochimica et Biophysica Acta, vol. 1801, no. 3, pp. 252-265, 2010.

[70] J. Todoric, M. Löffler, J. Huber et al., "Adipose tissue inflammation induced by high-fat diet in obese diabetic mice is prevented by n-3 polyunsaturated fatty acids," Diabetologia, vol. 49, no. 9, pp. 2109-2119, 2006.

[71] J. Huber, M. Löffler, M. Bilban et al., "Prevention of highfat diet-induced adipose tissue remodeling in obese diabetic mice by n-3 polyunsaturated fatty acids," International Journal of Obesity, vol. 31, no. 6, pp. 1004-1013, 2007.

[72] P. Perez-Martinez, F. Perez-Jimenez, and J. Lopez-Miranda, "n-3 PUFA and lipotoxicity," Biochimica et Biophysica Acta, vol. 1801, no. 3, pp. 362-366, 2010.
[73] X.-M. T. Nguyen, J. Lane, B. R. Smith, and N. T. Nguyen, "Changes in inflammatory biomarkers across weight classes in a representative US population: a link between obesity and inflammation," Journal of Gastrointestinal Surgery, vol. 13, no. 7, pp. 1205-1212, 2009.

[74] C. A. Aguilar-Salinas, E. García, L. Robles et al., "High adiponectin concentrations are associated with the metabolically healthy obese phenotype," Journal of Clinical Endocrinology and Metabolism, vol. 93, no. 10, pp. 40754079, 2008

[75] J.-Y. Kim, E. Van De Wall, M. Laplante et al., "Obesityassociated improvements in metabolic profile through expansion of adipose tissue," Journal of Clinical Investigation, vol. 117, no. 9, pp. 2621-2637, 2007.

[76] S. Neschen, K. Morino, J. C. Rossbacher et al., "Fish oil regulates adiponectin secretion by a peroxisome proliferatoractivated receptor- $\gamma$-dependent mechanism in mice," Diabetes, vol. 55, no. 4, pp. 924-928, 2006.

[77] A. Banga, R. Unal, P. Tripathi et al., "Adiponectin translation is increased by the PPAR $\gamma$ agonists pioglitazone and $\omega$-3 fatty acids," American Journal of Physiology, vol. 296, no. 3, pp. E480-E489, 2009.

[78] M. Itoh, T. Suganami, N. Satoh et al., "Increased adiponectin secretion by highly purified eicosapentaenoic acid in rodent models of obesity and human obese subjects," Arteriosclerosis, Thrombosis, and Vascular Biology, vol. 27, no. 9, pp. 19181925, 2007.

[79] R. H. Unger and Y.-T. Zhou, "Lipotoxicity of $\beta$-cells in obesity and in other causes of fatty acid spillover," Diabetes, vol. 50, supplement 1, pp. S118-S121, 2001.

[80] A. Baylin and H. Campos, "Arachidonic acid in adipose tissue is associated with nonfatal acute myocardial infarction in the Central Valley of Costa Rica," Journal of Nutrition, vol. 134, no. 11, pp. 3095-3099, 2004.

[81] P. M. Ridker, E. Danielson, F. A. H. Fonseca et al., "Rosuvastatin to prevent vascular events in men and women with elevated C-reactive protein," The New England Journal of Medicine, vol. 359, no. 21, pp. 2195-2207, 2008.

[82] J.-C. Fruchart and P. Duriez, "Mode of action of fibrates in the regulation of triglyceride and HDL-cholesterol metabolism," Drugs of Today, vol. 42, no. 1, pp. 39-64, 2006.

[83] D. B. Savage, "PPAR $\gamma$ as a metabolic regulator: insights from genomics and pharmacology," Expert Reviews in Molecular Medicine, vol. 7, no. 1, pp. 1-16, 2005.

[84] M. Studer, M. Briel, B. Leimenstoll, T. R. Glass, and H. C. Bucher, "Effect of different antilipidemic agents and diets on mortality: a systematic review," Archives of Internal Medicine, vol. 165, no. 7, pp. 725-730, 2005.

[85] S. E. Nissen and K. Wolski, "Effect of rosiglitazone on the risk of myocardial infarction and death from cardiovascular causes," The New England Journal of Medicine, vol. 356, no. 24, pp. 2457-2471, 2007.

[86] Y. Hattori, K. Suzuki, S. Hattori, and K. Kasai, "Metformin inhibits cytokine-induced nuclear factor $\kappa \mathrm{B}$ activation via AMP-activated protein kinase activation in vascular endothelial cells," Hypertension, vol. 47, no. 6, pp. 1183-1188, 2006.

[87] L. G. D. Fryer, A. Parbu-Patel, and D. Carling, "The antidiabetic drugs rosiglitazone and metformin stimulate AMPactivated protein kinase through distinct signaling pathways," Journal of Biological Chemistry, vol. 277, no. 28, pp. 2522625232, 2002. 
[88] A. K. F. Wong, J. Howie, J. R. Petrie, and C. C. Lang, "AMPactivated protein kinase pathway: a potential therapeutic target in cardiometabolic disease," Clinical Science, vol. 116, no. 8, pp. 607-620, 2009.

[89] A. Golay, "Metformin and body weight," International Journal of Obesity, vol. 32, no. 1, pp. 61-72, 2008.

[90] R. Christensen, P. K. Kristensen, E. M. Bartels, H. Bliddal, and A. Astrup, "Efficacy and safety of the weight-loss drug rimonabant: a meta-analysis of randomised trials," The Lancet, vol. 370, no. 9600, pp. 1706-1713, 2007.

[91] L. M. Beckman, T. R. Beckman, and C. P. Earthman, "Changes in gastrointestinal hormones and leptin after Roux-en-Y gastric bypass procedure: a review," Journal of the American Dietetic Association, vol. 110, no. 4, pp. 571-584, 2010.

[92] N. Rasmusen, On Speed: The Many Lives of Amphetamine, NYU Press, New York, NY, USA, 2009.

[93] H. M. Connolly, J. L. Crary, M. D. McGoon et al., "Valvular heart disease associated with fenfluramine phentermine," The New England Journal of Medicine, vol. 337, no. 9, pp. 581588, 1997.

[94] B. Sears, The Zone, Regan Books, New York, NY, USA, 1995.

[95] B. Sears, "Anti-inflammatory diets for obesity and diabetes," Journal of the American College of Nutrition, vol. 28, no. 1, supplement 1, pp. 482S-491S, 2009.

[96] J. D. Ramakers, R. P. Mensink, G. Schaart, and J. Plat, "Arachidonic acid but not eicosapentaenoic acid (EPA) and oleic acid activates NF- $\kappa$ B and elevates ICAM-1 expression in Caco-2 cells," Lipids, vol. 42, no. 8, pp. 687-698, 2007.

[97] J. Y. Lee, J. Ye, Z. Gao et al., "Reciprocal modulation of toll-like receptor-4 signaling pathways involving MyD88 and phosphatidylinositol 3-kinase/AKT by saturated and polyunsaturated fatty acids," Journal of Biological Chemistry, vol. 278, no. 39, pp. 37041-37051, 2003.

[98] J. Y. Lee, L. Zhao, H. S. Youn et al., "Saturated fatty acid activates but polyunsaturated fatty acid inhibits toll-like receptor 2 dimerized with Toll-like receptor 6 or 1," Journal of Biological Chemistry, vol. 279, no. 17, pp. 16971-16979, 2004.

[99] T. Suganami, K. Tanimoto-Koyama, J. Nishida et al., "Role of the Toll-like receptor $4 / \mathrm{NF}-\kappa \mathrm{B}$ pathway in saturated fatty acid-induced inflammatory changes in the interaction between adipocytes and macrophages," Arteriosclerosis, Thrombosis, and Vascular Biology, vol. 27, no. 1, pp. 84-91, 2007.

[100] A. Kennedy, K. Martinez, C.-C. Chuang, K. Lapoint, and M. Mcintosh, "Saturated fatty acid-mediated inflammation and insulin resistance in adipose tissue: mechanisms of action and implications," Journal of Nutrition, vol. 139, no. 1, pp. $1-4,2009$.

[101] H. Shi, M. V. Kokoeva, K. Inouye, I. Tzameli, H. Yin, and J. S. Flier, "TLR4 links innate immunity and fatty acid-induced insulin resistance," Journal of Clinical Investigation, vol. 116, no. 11, pp. 3015-3025, 2006.

[102] F. Kim, M. Pham, I. Luttrell et al., "Toll-like receptor-4 mediates vascular inflammation and insulin resistance in diet-induced obesity," Circulation Research, vol. 100, no. 11, pp. 1589-1596, 2007.

[103] X. Zhang, G. Zhang, H. Zhang, M. Karin, H. Bai, and D. Cai, "Hypothalamic IKKbeta/NF-kappaB and ER stress link overnutrition to energy imbalance and obesity," Cell, vol. 135, no. 1, pp. 61-73, 2008.
[104] A. Denys, A. Hichami, and N. A. Khan, "n-3 PUFAs modulate T-cell activation via protein kinase C- $\alpha$ and $-\varepsilon$ and the NF- $\kappa$ B signaling pathway," Journal of Lipid Research, vol. 46, no. 4, pp. 752-758, 2005.

[105] B. Romier, J. Van De Walle, A. During, Y. Larondelle, and Y. -J. Schneider, "Modulation of signalling nuclear factor- $\kappa \mathrm{B}$ activation pathway by polyphenols in human intestinal Caco2 cells," British Journal of Nutrition, vol. 100, no. 3, pp. 542551, 2008.

[106] J. Y. Lee, A. Plakidas, W. H. Lee et al., "Differential modulation of Toll-like receptors by fatty acids: preferential inhibition by $\mathrm{n}-3$ polyunsaturated fatty acids," Journal of Lipid Research, vol. 44, no. 3, pp. 479-486, 2003.

[107] C. von Schacky, "A review of omega-3 ethyl esters for cardiovascular prevention and treatment of increased blood triglyceride levels," Vascular Health and Risk Management, vol. 2, no. 3, pp. 251-262, 2006.

[108] H. Li, X. Z. Ruan, S. H. Powis et al., "EPA and DHA reduce LPS-induced inflammation responses in HK-2 cells: evidence for a PPAR- $\gamma$-dependent mechanism," Kidney International, vol. 67, no. 3, pp. 867-874, 2005.

[109] R. U. Pliquett, D. Führer, S. Falk, S. Zysset, D. Y. Von Cramon, and M. Stumvoll, "The effects of insulin on the central nervous system-focus on appetite regulation," Hormone and Metabolic Research, vol. 38, no. 7, pp. 442-446, 2006.

[110] H. Davidowa and A. Plagemann, "Insulin resistance of hypothalamic arcuate neurons in neonatally overfed rats," NeuroReport, vol. 18, no. 5, pp. 521-524, 2007.

[111] M. W. Schwartz and D. Porte Jr., "Diabetes, obesity, and the brain,” Science, vol. 307, no. 5708, pp. 375-379, 2005.

[112] P. J. Scarpace and Y. Zhang, "Leptin resistance: a prediposing factor for diet-induced obesity," American Journal of Physiology, vol. 296, no. 3, pp. R493-R500, 2009.

[113] S. S. Martin, A. Qasim, and M. P. Reilly, "Leptin resistance: a possible interface of inflammation and metabolism in obesity-related cardiovascular disease," Journal of the American College of Cardiology, vol. 52, no. 15, pp. 1201-1210, 2008.

[114] S. I. Rapoport, "Arachidonic acid and the brain," Journal of Nutrition, vol. 138, no. 12, pp. 2515-2520, 2008.

[115] S. Watanabe, M. Doshi, and T. Hamazaki, "n-3 polyunsaturated fatty acid (PUFA) deficiency elevates and n-3 PUFA enrichment reduces brain 2-arachidonoylglycerol level in mice," Prostaglandins Leukotrienes and Essential Fatty Acids, vol. 69, no. 1, pp. 51-59, 2003.

[116] C. T. Chen, Z. Liu, M. Ouellet, F. Calon, and R. P. Bazinet, "Rapid $\beta$-oxidation of eicosapentaenoic acid in mouse brain: an in situ study," Prostaglandins Leukotrienes and Essential Fatty Acids, vol. 80, no. 2-3, pp. 157-163, 2009.

[117] R. L. Batterham, H. Heffron, S. Kapoor et al., "Critical role for peptide YY in protein-mediated satiation and body-weight regulation," Cell Metabolism, vol. 4, no. 3, pp. 223-233, 2006.

[118] S. Chalon, "Omega-3 fatty acids and monoamine neurotransmission," Prostaglandins Leukotrienes and Essential Fatty Acids, vol. 75, no. 4-5, pp. 259-269, 2006.

[119] P. J. Sorgi, E. M. Hallowell, H. L. Hutchins, and B. Sears, "Effects of an open-label pilot study with highdose EPA/DHA concentrates on plasma phospholipids and behavior in children with attention deficit hyperactivity disorder," Nutrition Journal, vol. 6, article 16, 2007.

[120] M. Germano, D. Meleleo, G. Montorfano et al., "Plasma, red blood cells phospholipids and clinical evaluation after long chain omega-3 supplementation in children with attention 
defict hyperactivity disorder (ADHD)," Nutritional Neuroscience, vol. 10, no. 1-2, pp. 1-9, 2007.

[121] J.-T. Hwang, D. Y. Kwon, and S. H. Yoon, "AMP-activated protein kinase: a potential target for the diseases prevention by natural occurring polyphenols," New Biotechnology, vol. 26, no. 1-2, pp. 17-22, 2009.

[122] M. Zang, S. Xu, K. A. Maitland-Toolan et al., "Polyphenols stimulate AMP-activated protein kinase, lower lipids, and inhibit accelerated atherosclerosis in diabetic LDL receptordeficient mice," Diabetes, vol. 55, no. 8, pp. 2180-2191, 2006.

[123] M. Takikawa, S. Inoue, F. Horio, and T. Tsuda, "Dietary anthocyanin-rich bilberry extract ameliorates hyperglycemia and insulin sensitivity via activation of amp-activated protein kinase in diabetic mice," Journal of Nutrition, vol. 140, no. 3, pp. 527-533, 2010.

[124] C. S. Johnston, C. S. Day, and P. D. Swan, "Postprandial thermogenesis is increased $100 \%$ on a high-protein, lowfat diet versus a high-carbohydrate, low-fat diet in healthy, young women," Journal of the American College of Nutrition, vol. 21, no. 1, pp. 55-61, 2002.

[125] D. K. Layman and J. I. Baum, "Dietary protein impact on glycemic control during weight loss," Journal of Nutrition, vol. 134, no. 4, pp. 968S-973S, 2004.

[126] L. E. Norton, D. K. Layman, P. Bunpo, T. G. Anthony, D. V. Brana, and P. J. Garlick, "The leucine content of a complete meal directs peak activation but not duration of skeletal muscle protein synthesis and mammalian target of rapamycin signaling in rats," Journal of Nutrition, vol. 139, no. 6, pp. 1103-1109, 2009.

[127] D. K. Layman, "Dietary guidelines should reflect new understandings about adult protein needs," Nutrition and Metabolism, vol. 6, article 12, 2009.

[128] Institute of Medicine of the National Academies, Dietary Reference Intake for Energy, Carbohydrates, Fat, Fiber, Fatty Acids, Cholesterol, Protein, and Amino Acids, National Academies Press, Washington, DC, USA, 2002.

[129] F. M. Sacks, G. A. Bray, V. J. Carey et al., "Comparison of weight-loss diets with different compositions of fat, protein, and carbohydrates," The New England Journal of Medicine, vol. 360, no. 9, pp. 859-873, 2009.

[130] C. D. Gardner, A. Kiazand, S. Alhassan et al., "Comparison of the Atkins, Zone, Ornish, and LEARN diets for change in weight and related risk factors among overweight premenopausal women: the A to $\mathrm{Z}$ weight loss study: a randomized trial," Journal of the American Medical Association, vol. 297, no. 9, pp. 969-977, 2007.

[131] M. L. Dansinger, J. A. Gleason, J. L. Griffith, H. P. Selker, and E. J. Schaefer, "Comparison of the Atkins, Ornish, Weight Watchers, and Zone Diets for weight loss and heart disease risk reduction: a randomized trial," Journal of the American Medical Association, vol. 293, no. 1, pp. 43-53, 2005.

[132] D. K. Layman, "The role of leucine in weight loss diets and glucose homeostasis," Journal of Nutrition, vol. 133, no. 1, pp. 261S-267S, 2003.

[133] S. K. Raatz, C. J. Torkelson, J. B. Redmon et al., "Reduced glycemic index and glycemic load diets do not increase the effects of energy restriction on weight loss and insulin sensitivity in obese men and women," Journal of Nutrition, vol. 135, no. 10, pp. 2387-2391, 2005.

[134] C. B. Ebbeling, M. M. Leidig, H. A. Feldman, M. M. Lovesky, and D. S. Ludwig, "Effects of a low-glycemic load vs low-fat diet in obese young adults: a randomized trial," Journal of the American Medical Association, vol. 297, no. 19, pp. 20922102, 2007.
[135] A. G. Pittas, S. B. Roberts, S. K. Das et al., "The effects of the dietary glycemic load on type 2 diabetes risk factors during weight loss," Obesity, vol. 14, no. 12, pp. 2200-2209, 2006.

[136] A. G. Pittas, S. K. Das, C. L. Hajduk et al., "A low-glycemic load diet facilitates greater weight loss in overweight adults with high insulin secretion but not in overweight adults with low insulin secretion in the CALERIE trial," Diabetes Care, vol. 28, no. 12, pp. 2939-2941, 2005.

[137] M. A. Pereira, J. Swain, A. B. Goldfine, N. Rifai, and D. S. Ludwig, "Effects of a low-glycemic load diet on resting energy expenditure and heart disease risk factors during weight loss," Journal of the American Medical Association, vol. 292, no. 20, pp. 2482-2490, 2004.

[138] Joslin Diabetes Research Center Dietary Guidelines, http:// www.joslin.org/docs/nutrition_guideline_graded.pdf.

[139] O. Hamdy and C. Carver, "The why WAIT program: improving clinical outcomes through weight management in type 2 diabetes," Current Diabetes Reports, vol. 8, no. 5, pp. 413-420, 2008.

[140] B. Sears, Mastering the Zone, Regan Books, New York, NY, USA, 1997.

[141] R. R. Wing and S. Phelan, "Long-term weight loss maintenance," The American Journal of Clinical Nutrition, vol. 82, no. 1, supplement, pp. 222S-225S, 2005.

[142] R. R. Wing and J. O. Hill, "Successful weight loss maintenance," Annual Review of Nutrition, vol. 21, pp. 323-341, 2001. 


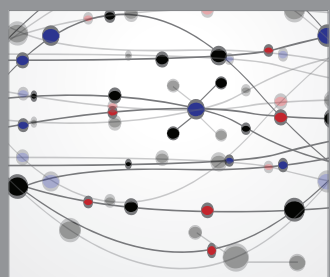

The Scientific World Journal
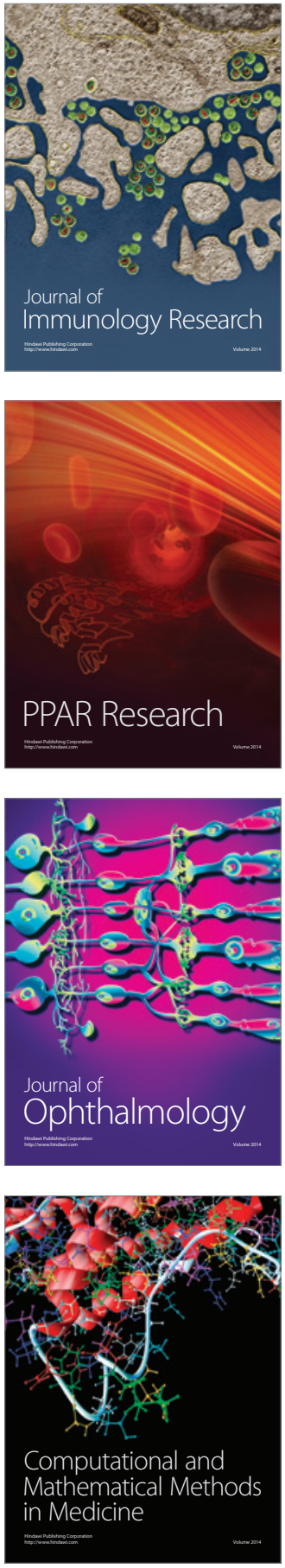

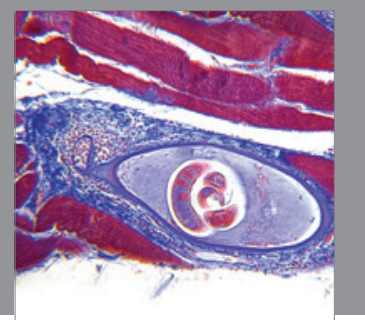

Gastroenterology

Research and Practice
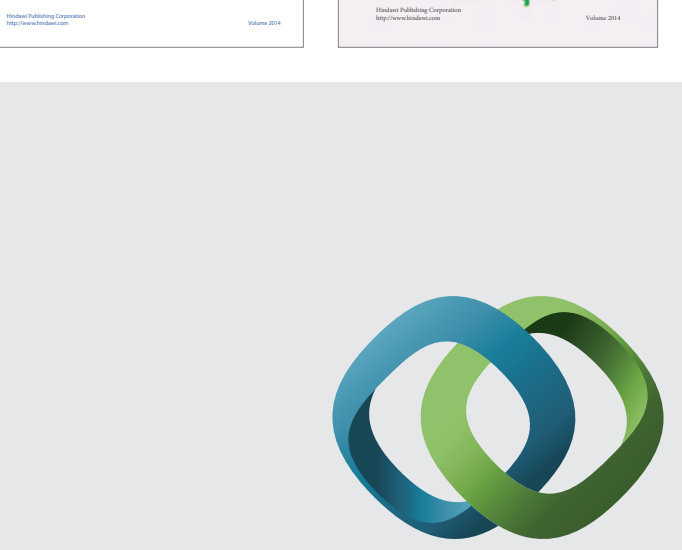

\section{Hindawi}

Submit your manuscripts at

http://www.hindawi.com
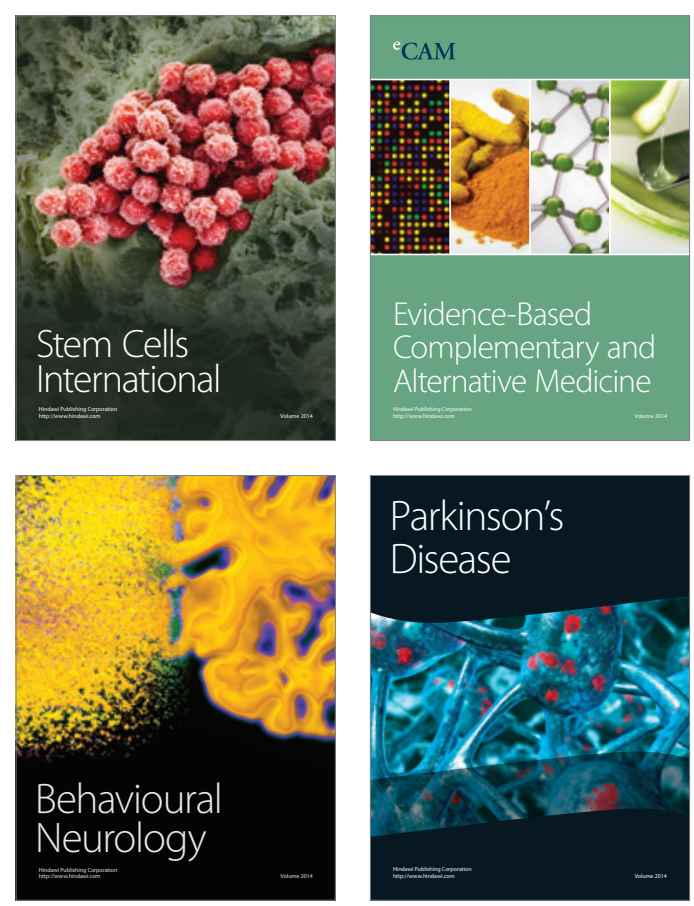

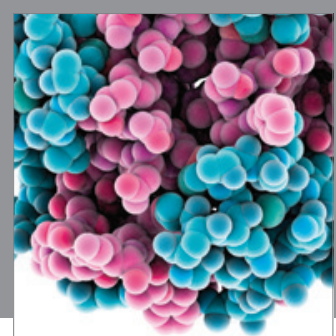

Journal of
Diabetes Research

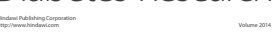

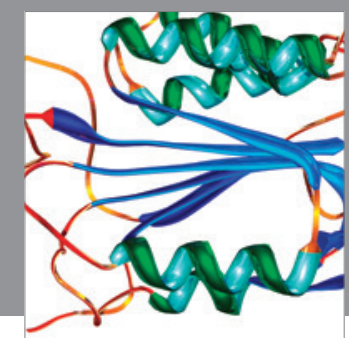

Disease Markers
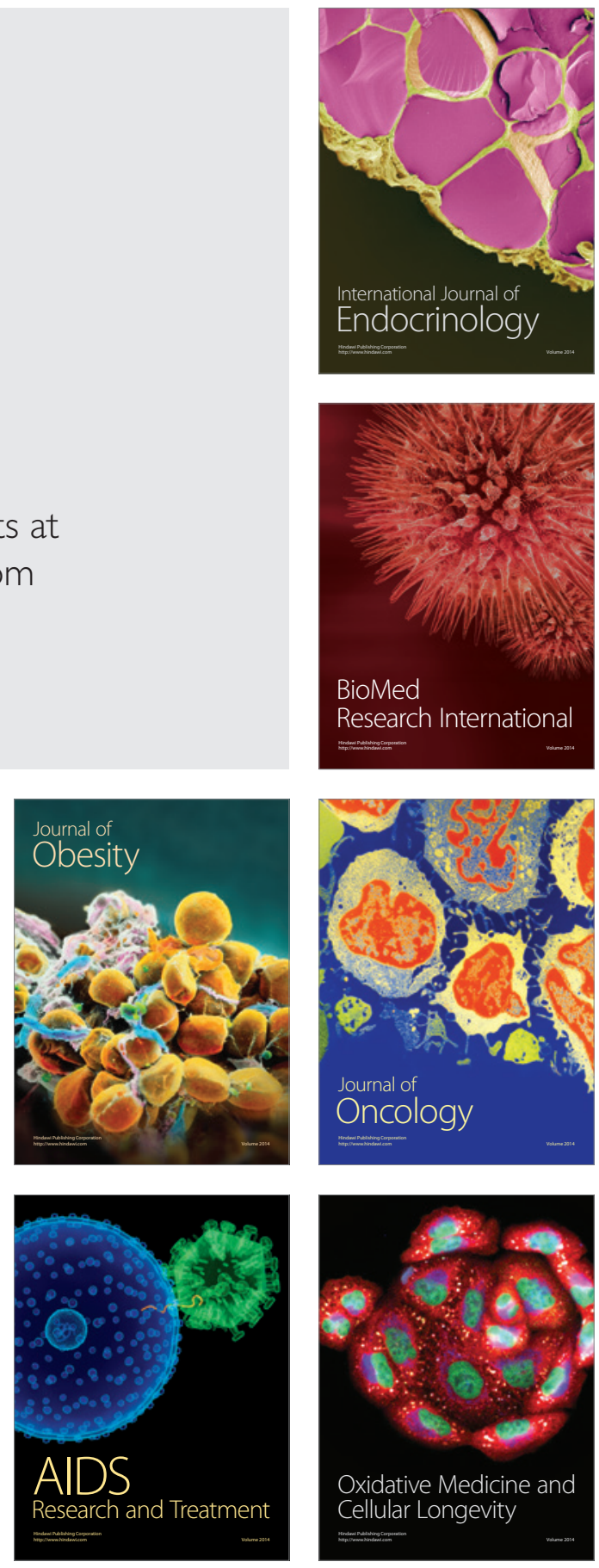